\title{
Hubungan Letak Lesi Strok Iskemik dengan Kualitas Tidur di RSAU dr. M. Salamun Bandung
}

\author{
Alya Tursina, ${ }^{1}$ Widayanti, ${ }^{2}$ Ariko Rahmat Putra ${ }^{3}$ \\ ${ }^{1}$ Departemen Neurologi, ${ }^{2}$ Departemen Fisiologi, ${ }^{3}$ Departemen Anatomi, \\ Fakultas Kedokteran Universitas Islam Bandung
}

\begin{abstract}
Abstrak
Prevalensi strok di Indonesia terus meningkat seiring dengan usia harapan hidup yang semakin meningkat dan menyebabkan banyak kematian. Pasien strok terutama strok iskemik dapat mengalami berbagai macam gangguan tidur. Macam gangguan tidur pada penderita strok bergantung pada defisit neurologis yang dialaminya. Tujuan penelitian ini mengetahui hubungan lokasi lesi strok iskemik daerah kortikal dan subkortikal dengan kualitas tidur menggunakan pemeriksaan Pittsburgh Sleep Quality Index (PSQI) di RSAU dr. M. Salamun Bandung. Penelitian ini merupakan penelitian observasional dengan rancangan penelitian potong lintang. Penelitian dilakukan terhadap 38 penderita yang pertama kali didiagnosis strok iskemik yang dirawat inap di Bagian Neurologi RSAU dr. M. Salamun Bandung pada bulan Juni sampai Oktober 2016. Instrumen penelitian berupa kuesioner PSQI yang dilakukan pada hari ke-7 pasien dirawat inap. Statistical for social science (SPSS) versi 17 digunakan untuk mengolah data. Hasil penelitian menunjukkan terdapat hubungan bermakna lokasi lesi strok iskemik daerah kortikal dan subkortikal dengan kualitas tidur $(\mathrm{p}=0,215)$. Penderita strok iskemik dengan lokasi lesi hipodens subkortikal yang mengalami gangguan kualitas tidur sebesar 23 dari 28 subjek dan lokasi lesi hipodens kortikal sebesar 3 dari 9 subjek.
\end{abstract}

Kata kunci: Kualitas tidur, letak lesi strok, strok iskemik

\section{Relationship between Ischemic Stroke Lesions and Sleep Quality at RSAU dr. M. Salamun Bandung}

\begin{abstract}
The prevalence of stroke in Indonesia continues to increase with increasing life expectancy and it causes many deaths. Stroke patients, especially ischemic stroke can experience a variety of sleep disorders. The types of sleep disorders in stroke patients depend on the neurological deficits they experience. The purpose of this study was to study the relationship between the location of cortical and subcortical ischemic stroke lesions with the quality of sleep using Pittsburgh Sleep Quality Index (PSQI) examination in RSAU dr. M. Salamun Bandung. This study was an observational study with a cross sectional study design. The study was conducted on 38 patients who were first diagnosed with a stroke in the Neurology Department of RSAU Dr. M. Salamun Bandung in June to October 2016. The research instrument consisted of the PSQI questionnaire conducted on the 7 th day of hospitalized patients. Version 17 of the social sciences statistics (SPSS) was used to process data. The results showed that there was a correlation between the location of cortical and subcortical ischemic stroke lesions with the quality of sleep $(\mathrm{p}=0.215)$. Ischemic stroke patients with subcortical hypodense lesions who experienced sleep quality disorders were 23 of 28 and patients with cortical hypodens lesions were 3 of 9 patients.
\end{abstract}

Keywords: Ischemic stroke, location of lesions stroke, sleep quality

Korespondensi: Alya Tursina. Departemen Neurologi, Fakultas Kedokteran, Universitas Islam Bandung, Jalan Taman Sari No. 22, 40116, Kota Bandung, Provinsi Jawa Barat, Email: alyanuryadin@gmail.com 


\section{Pendahuluan}

Strok merupakan penyebab kematian kedua setelah penyakit jantung dan penyebab disabilitas nomor satu di dunia. Menurut World Health Organization (WHO) pada tahun 2007 terdapat 15 juta orang mengalami strok setiap tahunnya dan angka ini akan terus meningkat seiring dengan faktor usia harapan hidup yang tinggi dan faktor risiko strok yang sulit dikendalikan. Di Amerika Serikat, strok menempati urutan ketiga penyebab kematian setelah penyakit jantung dan kanker. Data Nasional Strok di Indonesia menunjukkan penyebab kematian karena strok sebesar $15,4 \% .^{1-4}$

Prevalensi strok, di Indonesia ditemukan sebesar 8,3 per 1.000 penduduk dan yang terdiagnosis oleh tenaga kesehatan adalah 6 per 1.000 penduduk. Hal ini menunjukkan sekitar 72,3\% kasus strok di masyarakat telah didiagnosis oleh tenaga kesehatan dan berdasar atas data diagnosis tenaga kesehatan terdapat 11 provinsi di Indonesia termasuk Jawa Barat memiliki prevalensi strok di atas prevalensi nasional. ${ }^{2,4,5}$

Klasifikasi strok berdasar atas patologi anatomi dan penyebabnya terdiri atas strok iskemik dan strok perdarahan. Penelitian di RS Denmark menunjukkan bahwa angka kejadian strok iskemik lebih tinggi sebesar $89,9 \%$, sedangkan strok perdarahan $10,1 \%$. Di Cina dan Jepang pun menunjukkan strok iskemik sekitar 70-80\% dan strok perdarahan 20-30\%. ${ }^{6}$ Penelitian strok oleh Misbach dan $\mathrm{Ali}^{5}$ di Asia Tenggara, strok iskemik sebesar 74\%, sedangkan strok perdarahan $26 \%$.

Strok merupakan penyakit yang menyebabkan disabilitas populasi usia dewasa dunia dalam jumlah yang besar. Pasien strok sering kali tidak mendapatkan pelayanan rehabilitasi yang adekuat sehingga pada saat kembali bekerja mempunyai keterbatasan fungsi, kelemahan, gangguan tidur, dan gangguan psikologis. ${ }^{7}$

Pasien strok, terutama pada strok iskemik dapat mengalami berbagai macam gangguan tidur. Macam gangguan tidur pada penderita strok bergantung pada defisit neurologis yang dialaminya. Sleep disorder breathing (SDB) terutama obstructive sleep apnea syndrome (OSAS) paling sering ditemukan pada pasien strok (lebih dari 50\%). SDB akibat strok terutama disebabkan oleh gangguan pada pusat pernapasan di brainstem atau paralisis bulbar/pseudobulbar. ${ }^{8}$ Gangguan tidur lain yang dapat terjadi pada pasien strok adalah circadian rhythm disorder atau sleepwake disorder (SWD) mengenai 20-40\% penderita strok dan insomnia. ${ }^{9}$ Gangguan saraf yang berkaitan dengan jenis gangguan tidur ini adalah gangguan impuls saraf ke nukleus suprakiasma. ${ }^{7}$

Oleh karena itu, peneliti tertarik mengetahui hubungan lokasi lesi strok iskemik daerah kortikal dan subkortikal dengan kualitas tidur menggunakan pemeriksaan Pittsburgh Sleep Quality Index (PSQI) di RSAU dr. M. Salamun Bandung.

\section{Metode}

Jenis penelitian ini adalah observasional dengan rancangan penelitian potong lintang terhadap 39 pasien sesuai dengan rumus sampel minimal menurut
Lemeshowb berdasar atas kedatangan (consecutive admission sampling).

Subjek penelitian adalah pasien yang dirawat inap di Bagian Neurologi RSAU dr. M. Salamun Bandung mulai Juni sampai Oktober 2016 yang memenuhi kriteria inklusi, yaitu memiliki kesadaran komposmentis, didiagnosis strok itu pertama kali dibuktikan dengan CT-scan kepala tanpa kontras, dan pasien tersebut mengalami gangguan tidur. Peneliti melakukan anamnesis, pemeriksaan fisis, dan pemeriksaan neurologi, neuroimaging CT-scan kepala, dan menggunakan kuesioner Pittsburgh Sleep Quality Index (PSQI) pada hari ke-7 pasien rawat inap strok iskemik untuk menilai kualitas tidur. Uji statistik yang dipergunakan adalah metode chi square dengan SPSS versi 17.

\section{Hasil}

Karakteristik subjek penelitian berdasar atas usia dan jenis kelamin penderita yang dirawat di Bagian Neurologi RSAU dr. M. Salamun Bandung dapat dilihat pada Tabel 1.

\begin{tabular}{|c|c|c|}
\hline Tabel 1 & \multicolumn{2}{|c|}{$\begin{array}{l}\text { Karakteristik Subjek Penelitian } \\
\text { berdasar atas Usia dan Jenis } \\
\text { Kelamin Penderita yang Dirawat } \\
\text { di Bagian Neurologi RSAU dr. M. } \\
\text { Salamun Bandung }\end{array}$} \\
\hline & Variabel & $\mathbf{n}=\mathbf{3 9}$ \\
\hline \multicolumn{3}{|c|}{ Usia (tahun) } \\
\hline & -50 & 4 \\
\hline & -60 & 12 \\
\hline & -70 & 14 \\
\hline & $>70$ & 9 \\
\hline Rerata & D): $62,59(9,97)$ & Minimum: 42 \\
\hline Median & & Maksimum: 87 \\
\hline \multicolumn{3}{|c|}{ Jenis kelamin } \\
\hline Laki & aki & 16 \\
\hline Pere & ipuan & 23 \\
\hline
\end{tabular}

Rerata usia penderita yang dirawat 62,59 tahun, simpangan baku 9,97 tahun, median 63 tahun, usia paling muda 42 tahun, usia paling tua 87 tahun, sebagian besar usia 61-70 tahun, dan lebih banyak perempuan.

Karakteristik subjek penelitian berdasar atas lokasi lesi strok iskemik dengan kualitas tidur menggunakan pemeriksaan PSQI di RSAU dr. M. Salamun Bandung dapat dilihat pada Tabel 2.

Tabel 2 menunjukkan bahwa berdasar atas lokasi lesi strok iskemik daerah kortikal dan subkortikal dengan kualitas tidur menggunakan pemeriksaan PSQI di RSAU dr. M. Salamun Bandung lebih banyak lesi hipodens subkortikal kanan sebanyak 15 orang.

Karakteristik subjek penelitian berdasar atas kualitas tidur menggunakan pemeriksaan PSQI di RSAU dr. M. Salamun Bandung dapat dilihat pada Tabel 3 . 
Tabel 2 Karakteristik Subjek Penelitian berdasar atas Lokasi Lesi Strok Iskemik Daerah Kortikal dan Subkortikal dengan Kualitas Tidur Menggunakan Pemeriksaan PSQI di RSAU dr. M. Salamun Bandung

\begin{tabular}{lc}
\hline Lokasi Lesi Strok Iskemik & $\mathbf{n = 3 9}$ \\
\hline Lesi hipodens subkortikal kiri & 13 \\
Lesi hipodens subkortikal kanan & 15 \\
Lesi hipodens kortikal kiri & 6 \\
Lesi hipodens kortikal kanan & 3 \\
Lesi hipodens serebellum & 1 \\
Lesi hipodens pons & $\mathbf{1}$ \\
\hline
\end{tabular}

Tabel 3 Karakteristik Subjek Penelitian berdasar atas Kualitas Tidur Menggunakan Pemeriksaan PSQI di RSAU dr. M. Salamun Bandung

\begin{tabular}{ll}
$\begin{array}{l}\text { Kualitas Tidur Menggunakan } \\
\text { Pemeriksaan PSQI }\end{array}$ & $\mathbf{n = 3 9}$ \\
\hline Rerata (SD): $7,82(3,05)$ & \\
Median: 8 & \\
Minimum: 3 & \\
Maksimum: 14 & \\
Baik & 10 \\
Buruk & 29 \\
\hline
\end{tabular}

Sebagian besar kualitas tidur menggunakan pemeriksaan PSQI di RSAU dr. M. Salamun Bandung adalah buruk sebanyak 39 orang.

Hubungan lokasi lesi strok iskemik daerah kortikal dan subkortikal dengan kualitas tidur menggunakan pemeriksaan PSQI di RSAU dr. M. Salamun Bandung dapat dilihat pada Tabel 4.

Kualitas tidur buruk berdasar atas pemeriksaan PSQI lebih banyak terjadi pada lokasi lesi hipodens subkortikal sebesar 23 dari 28 subjek dibanding dengan lokasi lesi strok iskemik lainnya. Kualitas tidur yang baik berdasar atas pemeriksaan PSQI lebih banyak terjadi pada lokasi lesi hipodens kortikal sebesar 3 dari 9 subjek dibanding dengan lokasi lesi strok iskemik lainnya.

Hasil analisis dengan chi square test pada derajat kepercayaan 95\% menunjukkan bahwa secara statistik terdapat hubungan bermakna lokasi lesi strok iskemik daerah kortikal dan subkortikal dengan kualitas tidur menggunakan pemeriksaan PSQI di RSAU dr. M. Salamun Bandung dengan nilai $\mathrm{p}=0,215(\mathrm{p} \leq \mathrm{0}, 05)$.

\section{Pembahasan}

Siklus tidur-terjaga diregulasi oleh dua mekanisme biologis yang terpisah di dalam tubuh, dan proses ini menyeimbangkan satu sama lain. Dua proses regulasi tidur-terjaga ini adalah irama sirkadian dan homeostasis tidur-terjaga. Irama sirkadian dikenal sebagai proses internal tubuh dan tingkat kewaspadaan yang diatur oleh hipotalamus yang terletak di subkortikal sebagai pusat jam biologis sirkadian tubuh yang mengontrol waktu tidur. Homesotasis tidurterjaga merupakan akumulasi substansi hipnogenik di otak sebagai sistem biokimia internal yang beroperasi sebagai alat pengatur waktu yang menciptakan homeostatic sleep drive atau dorongan untuk tidur dan meregulasi intensitas tidur. Studi MRI fungsional berdasar atas mekanisme serebral dan homeostasis menemukan bahwa gugus tugas korteks dan subkorteks terkait dengan blood oxygen level dependent (BOLD) bila menurun akan memengaruhi kerentanan individu lebih tinggi terjadi gangguan tidur dan gangguan irama sirkadian. Pada pasien strok iskemik BOLD akan menurun terutama pada lokasi infark sehingga bila infark terjadi pada daerah subkortikal semestinya akan menyebabkan gangguan kualitas tidur menjadi buruk dibanding dengan daerah kortikal. Namun demikian, daerah kortikal pun mendapat pancaran dari ascending reticular activating system (ARAS) sehingga dapat terjadi gangguan kualitas tidur. ${ }^{10}$

Gambaran kualitas tidur dapat diukur dengan mempergunakan kuesioner. Kuesioner yang sering dipergunakan di antaranya adalah Pittsburgh Sleep Quality Index (PSQI), Insomnia Symptom Questionnaire, dan The Athens Insomnia Scale. Setiap kuesioner memiliki manfaat dan keterbatasan dalam

Tabel 4 Hubungan Lokasi Lesi Strok Iskemik Daerah Kortikal dan Subkortikal dengan Kualitas Tidur Menggunakan Pemeriksaan PSQI di RSAU dr. M. Salamun Bandung

\begin{tabular}{lcccc}
\hline \multirow{2}{*}{$\begin{array}{c}\text { Lokasi Lesi Strok Iskemik Daerah } \\
\text { Kortikal/Subkortikal }\end{array}$} & \multicolumn{3}{c}{ Kualitas Tidur Menggunakan Pemeriksaan } \\
\cline { 2 - 4 } & Buruk & Baik & Total \\
& $\mathbf{n = 2 9}$ & $\mathbf{n = 1 0}$ & $\mathbf{n = 3 9}$ \\
\hline Lesi hipodens subkortikal & 23 & 5 & 28 \\
Lesi hipodens kortikal & 6 & 3 & 9 & $\mathbf{0 , 0 3 6}$ \\
Lesi hipodens serebellum dan pons & 0 & 2 & 2 & \\
\hline
\end{tabular}

*) Chi square test kualitas tidur 
menilai persepsi tidur pasien. Pittsburgh Sleep Quality Index mengevaluasi kuantitas dan aspek tidur secara subjektif berupa kedalaman dan kenyamanan tidur. Hasil PSQI $0-5$ mengindikasikan pasien memiliki kualitas tidur yang baik, sedangkan bila lebih dari 5 mengindikasikan kualitas tidur yang buruk. Penelitian di Soonchunhyang University Hospital, Korea menunjukkan skor PSQI pada 80 pasien strok adalah $8,1 \pm 4,1$ dengan $71,2 \%$ pasien memiliki kualitas tidur yang buruk. ${ }^{7}$

Hasil penelitian ini bila dilihat hubungan lokasi lesi iskemik kiri dan kanan dengan gangguan kualitas tidur sesuai dengan hasil penelitian Derfiani ${ }^{10}$ di RS Wahidin Sudirohusodo Makassar menunjukkan bahwa 55\% pasien strok iskemik mengalami gangguan kualitas tidur buruk dan $81,8 \%$ lesi infarknya terdapat pada hemisfer kanan. Hasil statistik menunjukkan bahwa terdapat hubungan yang signifikan kualitas tidur dengan lokasi infark. ${ }^{11}$ Pada penelitian ini didapakan lesi hipodens subkortikal kanan 15 dari 39 lebih banyak mengalami gangguan kualitas tidur dibandingkan dengan lesi subkortikal kiri 13 dari 39 orang.

Hasil analisis chi square test pada derajat kepercayaan 95\% menunjukkan bahwa secara statistik terdapat hubungan bermakna lokasi lesi strok iskemik daerah kortikal dan subkortikal dengan kualitas tidur menggunakan pemeriksaan PSQI di RSAU dr. M. Salamun Bandung. Kualitas tidur yang buruk berdasar atas pemeriksaan PSQI lebih banyak terjadi pada lokasi lesi hipodens subkortikal dibanding dengan lokasi lesi strok iskemik lainnya. Kualitas tidur yang baik berdasar atas pemeriksaan PSQI lebih banyak terjadi pada lokasi lesi hipodens kortikal dibanding dengan lokasi lesi strok iskemik lainnya. Lesi hipodens pada serebelum dan pons mempunyai kualitas tidur yang baik, hal ini tidak sesuai dengan teori karena nukleus suprakiasmatik sebagai pusat kendali tidur berada di pons, namun dimungkinkan bila lesi hipodens sangat kecil atau hanya berupa lesi lakuner sehingga tidak memengaruhi kualitas tidur.

\section{Simpulan}

Terdapat hubungan lokasi lesi strok iskemik daerah kortikal dan subkortikal dengan kualitas tidur menggunakan pemeriksaan PSQI di RSAU dr. M. Salamun Bandung.

\section{Ucapan Terima kasih}

Terima kasih kami ucapkan kepada Direktur beserta staf RSAU dr. M. Salamun Bandung.

\section{Daftar Pustaka}

1. Sacco RL, Kasner SE, Broderick JP, Caplan LR, Connors JJ, Culebras A, dkk. An updated definition of strok for healthcare professionals from the American Heart Association/American Strok Association. J AHA. 2013;44(7):2064-89.

2. Jones DL, Adams RJ, Brown TM, Carnethon M, Dai S, Simone GD, dkk. Heart disease and strok statistics 2010 update: a report from the American Heart Association. J AHA. 2010;121(7):e46-e215.

3. Badan Penelitian dan Pengembangan Kesehatan. Proporsi penyebab kematian pada kelompok umur 55-64 tahun menurut tipe daerah. Laporan Hasil Riset Kesehatan Dasar (Riskesdas) Nasional 2007. Jakarta: Departemen Kesehatan Indonesia; 2018.

4. Kusuma Y, Venketasubramanian N, Kiemas L, Misbach J. Burden of stroke in Indonesia. Int J Stroke. 2009 Oct;4(5):379-80.

5. Misbach J, Ali W. Stroke in Indonesia: a first large prospective hospital based study of acute strok in 28 hospitals in Indonesia. J Clin Neurol. 2000;8(3):245-9.

6. Klaus KA, Tom SO, Christian D, Lars PK. Hemorrhagic and ischemic strok compared, strok severity, mortality and risk factor. J AHA. 2009;40:2068-72.

7. Kim J, Kim Y, Yang KI, Kim D, Kim A. The relationship between sleep disturbance and functional status in mild strok patients. Ann Rehabil Med. 2015;39(4):545-52.

8. Jennum P, Cano JS, Bassetti C, Clarenbach $\mathrm{P}$, Holg B, Mathis J, dkk. Sleep disorders in neurodegenerative disorder and stroke. Dalam; European handbook of neurological management. Volume 1. Edisi ke-2. Hoboken, New Jersey: Blackwell Publishing Ltd; 2011. hlm. 529-38.

9. National Stroke Association. Recovery after stroke: sleep disorders. 2006.

10. Derfiani PH. Correlation between sleep quality and cerebral infarction location. Kumpulan naskah ilmiah dan abstrak, INASleep, Perdossi Cabang Bandung, FKUP-RSHS. September 2016.

11. Dwipa L. Proses menua, ritme sirkadian dan tidur. dalam Kumpulan Naskah Ilmiah dan Abstrak, INASleep, Perdossi Cabang Bandung, FKUPRSHS. September 2016. 